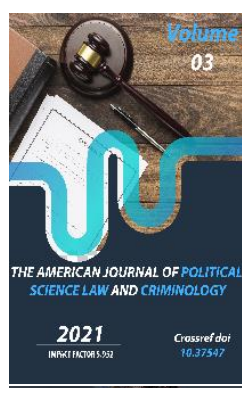

\title{
Processes For The Prevention Of Domestic Violence Against Children In Uzbekistan
}

\author{
Shavkat Ganiev \\ Senior Lecturer Of The Institute National Institute Of Art And Design, Tashkent, Uzbekistan
}

Journal Website: http://usajournalshub.c om/index,php/tajpslc

Copyright: Original content from this work may be used under the terms of the creative commons attributes 4.0 licence.

\section{ABSTRACT}

This article addresses topical issues of protection of children from domestic violence in the national legal system. Special attention is paid to the forms of domestic violence, protection of the rights and freedoms of victims.

\section{KEYWORDS}

Child, child rights, domestic violence, physical violence, mental violence, sexual violence, economic violence, cyber violence, social rehabilitation.

\section{INTRODUCTION}

It is known that the root of any offense and negative vices is formed in the family. The family plays an important role in the formation of human qualities, such as preparing a person for social life, spiritual and moral upbringing, behavior in the process of social relations with individuals. Today, 40 percent of crimes against life and health, one in four murders, one in five 
intentional bodily harm, and one in eight insults and slander are committed in the domestic sphere. President of the Republic of Uzbekistan Sh. Mirziyoyev: "I am personally deeply disturbed by the unhealthy relationships in the families, the quarrels between the mothers-in-law, the couples, and the suicides among our women," he said. [1].

The national legislation of all countries of the world places special emphasis on ensuring human rights and freedoms, in particular the protection of the life, health, honor and dignity of children from various criminal encroachments. The Universal Declaration of Human Rights recognizes that "the recognition of the inherent dignity and of equal, inalienable rights of all members of the human family is the foundation of freedom, justice and universal peace".

All can be victims of violence, but given the high probability of children being victims of violence, the types of violence, the severity, and the dramatic consequences, the latest reforms are aimed at protecting children who are socially vulnerable.

\section{MATERIALS AND METHODS}

The high latency of this problem is that victims understand the violence as part of a normal life or family upbringing, do not go anywhere or do not know the right to appeal in order not to tarnish the image of their parents or peers.

Violence against children includes all forms of violence committed by parents or other guardians, peers or strangers against people under the age of 18 .
Nearly 1 billion children between the ages of 2 and 17 worldwide are physically, sexually, or emotionally abused or neglected each year [3].

Violence in childhood affects health and wellbeing throughout life. Types and forms of violence against children. Physical violence inflicting bodily injuries of varying severity, endangering, failing to assist a person whose life is in danger, committing other offenses of a violent nature, threatening to inflict physical harm or other means of such infliction.

Physical violence can include the following:

- Slapping, kicking, pushing, punching;

- Pushing with a punch;

- Throwing various sharp objects;

- Physical inability to leave the house;

- $\quad$ Forced labor, forced working in night shifts with difficult working conditions;

- Not to sleep at night and so on.

Mental violence is the act of insulting, slandering, threatening children, humiliating their honor, dignity, controlling the reproductive sphere, causing concern for their own safety, inability to defend themselves, or harming their mental health (inaction).

Psychological violence can include the following:

- Lack of recognition of the child's interests and feelings;

- Laughing at the child's thoughts;

- Ignoring the feelings of the victim as a punishment;

- To lie and use it for personal gain;

- Threatening his friends and relatives (property);

- Refusal to go to public places with the victim;

- Shame among relatives; 
- Threatening to leave the house;

- Refusal to help him when he is sick;

- Resistance to education (as if you were going to study in the city);

- Violence against children who have passed away as caregivers (foster children, orphans, orphans, etc.

- Constant criticism, resentment, anger, ie (you are very lazy or "second", you are an animal, you are not a child, it is better to be born a girl, or vice versa), etc.

Sexual acts against children, as well as coercion or threat of violence, or coercion to have sex with a third party by committing immoral acts against female minors.

Sexual violence includes:

- All forms of homosexuality;

- Forcing to watch sexually explicit films;

- Satisfaction of sexual needs by unnatural means;

- Rape of minors, etc.

Action (inaction) that restricts the exercise of children's right to food, housing and other necessary conditions for normal life and development, the right to property, the right to education and the right to work).

Economic violence can include the following:

- Unreasonable non-payment for basic needs (food, clothing, medicine);

- Restriction of the right to use housing;

- Not to be allowed to study or work;

- Control how much money is spent;

- Not to waste his money;

- Is reflected in the application of the principle of balance in the use of the family budget.

\section{RESULTS AND DISCUSSION}

Another type of violence that is prevalent today is cyberbullying. This type of violence is characterized by the continuing, repetitive, and prolonged use of the Internet to degrade someone's honor and dignity. The anonymity of the perpetrator of psychological violence is marked by the fact that unpleasant messages are spread through the Internet day and night, causing great suffering to the victim. Using the Internet, the place of work or study is characterized by the spread of various insults, slander, slander, rumors, fabricated messages in the family. We can also recognize the use of the Internet and social networks as scenes of cruelty and violence that have a profound effect on a person's psyche, as well as games that promote suicide.

Domestic violence against children differs from acts committed in the workplace and in educational institutions:

- The abuser has full control over the victim, there is no possibility for the victim to escape from the abuser and remain safe;

- Violence is committed in order for one person to dominate and control another;

- Almost all family members suffer from violence;

- There is an emotional connection between the abuser and the victim.

The victim may feel a strong emotional attachment to the abuser and may side with the abuser when a third party seeks help. Such behavior of the victim is known in psychology as "Stockholm syndrome". Community members are reluctant to interfere in family affairs, and victims themselves prefer to remain silent about the situation in the family. Domestic violence is cyclical. Domestic 
violence against children can be conditionally divided into a cycle of four stages and increasing repetition.

1. Increased tension in the family. Relationships between family members change and resentment increases. The victim tries to justify himself, to claim his rights.

2. Violence. Mental, physical, or other types of violence escalate and are accompanied by intense anger, threats, intimidation.

3. Reconciliation period. The perpetrator apologizes and explains the reason for the violence or blames the victim. Sometimes he denies the violence and accuses the victim of exaggerating himself.

4. A period of peace in the relationship ("happy family"). The situation of violence was forgotten and the violence was forgiven. Pre-conflict relationships return, and before the next conflict begins, the “happy family era" begins.

Today, in order to protect children from violence, measures are being taken to create an atmosphere of intolerance to oppression and violence against children in society. In particular, our country has ratified a number of international documents on the protection of children from violence. International human rights instruments strengthen the mechanism for protecting children from violence, including criminal violence in the family. The Universal Declaration of Human Rights, the International Covenant on Civil and Political Rights, and the International Covenant on Economic, Social, and Cultural Rights recognize the family as a community-based group and protect the child from domestic violence.

Article 14 of the Family Code of the Republic of Uzbekistan stipulates that marriage is voluntary, and Article 19 states that husband and wife enjoy equal rights and responsibilities in the family [4]. Article 79 of the Code provides for abuse of parental rights, ill-treatment of children, including the use of physical force or psychological influence; it is established that he may be deprived of parental rights if he has committed an intentional crime against the life or health of his children or the life or health of his husband (wife). The Code of Administrative Responsibility of the Republic of Uzbekistan contains norms establishing liability for types of violence. In particular, Article 47 of the Criminal Code stipulates "failure to fulfill obligations for the upbringing and education of children", Article 473 - violation of the legislation on marriage age, Article 474 - refusal to provide financial support to minors or disabled people, Article 52 - minor injuries. The responsibility for the species is defined.

An analysis of the behavior of children who have been victims of domestic or other forms of violence suggests that they have the following characteristics:

- The victim is inhumane, reluctant to communicate with family members and relatives;

- Deep self-esteem, deep distress over the humiliation of honor and dignity;

- Show feelings of frustration due to fear and anxiety;

- Neglect of his appearance, natural needs, often thinking about suicide or attempting to commit suicide;

- Lack of food or excessive consumption, desire to consume alcohol, drugs;

- Rolling his eyes during communication, shedding tears, mistrusting people;

- Indifference or aggression towards their relatives. 
Children, the elderly, and women are more likely to be victims of domestic violence. In many cases, it is the victims of domestic violence who do not seek redress from the police or medical authorities. This is most often seen in women and children. When investigating information obtained from the judiciary, they try not to disclose information about the abuse of children by their parents, to conceal such cases, or to explain that they received the bodily injury as a result of their negligence, even if they sought medical help. The main reason for this can be explained by the fact that children are afraid of the separation of their parents, trying not to divulge family secrets.

\section{CONCLUSION}

The new Uzbek government's cooperation with the International Labor Organization, the expansion of education on forced labor and child labor, mechanization of the cotton harvest, the government's plan to reduce the area under cotton, as well as violations of the law on forced and (or) child labor from 2016 The introduction of the release system was also one of the first important steps in preventing the exploitation of child labor.

In our country, comprehensive measures are being taken to prevent crime, in particular, to raise the legal awareness and culture of the population, to improve cooperation between government agencies and civil society institutions. In particular, the Action Strategy for the five priority areas of development of the Republic of Uzbekistan for 2017-2021 includes increasing the responsibility of parents to control the behavior of children from troubled families, unorganized youth, unemployed youth affected by "popular culture". prevention of smoking, alcohol consumption and other diseases [5]".

\section{REFERENCES}

1. Mirziyoev Sh. M. Let us be more united and work resolutely for the fate and future of our country. // People's word. - T., 2017. June 16.

2. Universal Declaration of Human Rights (December 10, 1948)/ United Nations.

3. World Report on Violence against Children. - T., 2009. - B. 61

4. Family Code of the Republic of Uzbekistan // https://lex.uz/docs/104720\#158601

5. Decree of the President of the Republic of Uzbekistan dated February 7, 2017 No PF4947 "On the Strategy of further development of the Republic of Uzbekistan" // Collection of Legislation of the Republic of Uzbekistan, 2017, № 6., Article 70. 